\title{
EL FIN DE UNA ETAPA EXITOSA LOS TLC EN LA ESTRATEGIA COMERCIAL DE CHILE
}

Alfonso Dingemans*

T os tratados de libre comercio (TLC) han sido el principal insLtrumento de la estrategia comercial chilena desde la década de 1990, y Chile es quizá el país que más TLC ha firmado en el mundo. Ese énfasis es comprensible en vista del objetivo de aumentar las exportaciones. Un objetivo determinado por la organización económica que establecieron las reformas neoliberales de los años ochenta, las cuales suponían que la competencia internacional era la principal fuerza dinamizadora de la economía chilena. Así, la política comercial se basó en el "nexo entre exportaciones y crecimiento" (Dingemans y Ross, 2012), es decir, que el aumento de las exportaciones llevaría al crecimiento y al desarrollo. Esta cadena causal depende de su capacidad para crear valor agrado (Agosín, 2000) y, por ende, de la capacidad para innovar.

Si bien la nueva organización económica presupone que el mercado dictamina la dirección y la velocidad del desarrollo económico, y no el Estado como en la época de la industrialización por sustitución de importaciones (ISI); y por tanto que la estrategia de desarrollo -y en particular la comercial- debe ser guiada por el mercado, el papel del Estado se concibe según el principio estricto de subsidiariedad. Como pueden surgir fallas de mercado que no resuelven los agentes privados, el Estado debe intervenir para apagar los incendios y hacer posible que esos agentes sigan su camino. La aplicación de este principio se

* Doctor en Estudios Americanos, profesor asistente, Departamento de Historia, Universidad de Santiago de Chile, [alfonso.dingemans@usach.cl]. Fecha de recepción: 9 de julio de 2014, fecha de modificación: 15 de abril de 2016, fecha de aceptación: 12 de mayo de 2016. Sugerencia de citación: Dingemans, A. "E1 fin de una etapa exitosa. Los TLC en la estrategia comercial de Chile", Revista de Economía Institucional 18, 34, 2016, pp. 151-172. DOI: http://dx.doi. org/10.18601/01245996.v18n34.10 
condensa en el prolífico uso de los "fondos concursables", a través de los cuales el Estado entrega al sector privado recursos que serán evaluados por su calidad técnica, y que en realidad son un subsidio a la demanda. No se evalúa la coherencia de los proyectos adjudicados (la evaluación es contable), y tampoco los indicadores de impacto; de modo que las decisiones a nivel de empresas no son afectadas por esta intervención del Estado.

Este artículo argumenta que esas reglas del juego mejoraron el acceso de los productos chilenos a los mercados extranjeros pero no su calidad (ni su valor agregado), principalmente porque es difícil reconstituir la estructura productiva a través del mercado, como muestra la evidencia empírica (Devlin y Moguillansky, 2010). El éxito chileno ha sido cuantitativo; la calidad del crecimiento -y también de las exportaciones- es decepcionante: la economía sigue dependiendo de las exportaciones de cobre. Para modificar esta situación se requieren nuevas instituciones o reglas del juego que abandonen el principio de las "políticas horizontales" supuestamente neutras, que den comienzo a una nueva etapa en la estrategia comercial y eviten que Chile caiga -o se mantenga- en la "trampa del ingreso medio": el estancamiento del desarrollo económico. Pues aunque el Banco Mundial lo catalogue como un país de altos ingresos, su estructura productiva no corresponde a la de ese tipo de países.

$\mathrm{E} 1$ artículo sostiene que la estrategia comercial, entendida como un plan multisectorial que busca superar los obstáculos para lograr un objetivo (Rumelt, 2011), basada en los TLC está cerrando una etapa exitosa en términos del aumento de las exportaciones y de su valor total, y en menor medida de la diversificación. Para aumentar su complejidad y su valor agregado se requiere una estrategia que desafíe las ventajas comparativas de manera más articulada y eficaz.

En la primera sección se revisa la apertura de la economía desde los años setenta, y después se describen los aportes (cambios y continuidades) de los gobiernos de la Concertación. Después se analiza la estrategia comercial para mostrar que no logró diversificar las exportaciones ni elevar el valor agregado. Luego se evalúa la capacidad institucional para adoptar una estrategia que no esté guiada exclusivamente por el mercado. Al final se presentan las conclusiones.

\section{EL NUEVO IMPULSO A LAS EXPORTACIONES}

En una revisión de la historia económica de Chile desde la Independencia, Pinto y Salazar (2002) señalan que esta ha sido marcada por una vocación exportadora, pese al interludio relativo en la época de 
1a ISI. La apertura de la economía durante el régimen militar (19731990) fue uno de los pilares de las profundas reformas económicas de ese periodo. $\mathrm{El}$ agotamiento del proyecto industrializador, reflejado en los magros resultados de la etapa "difícil" de la industrialización por un lado, y en no menor medida el ataque a la propiedad privada durante los mil días de Allende por otro, propiciaron el discurso anti estatista. El diagnóstico que se impuso en el diseño de la nueva política económica, inducido principal pero no exclusivamente por los Chicago boys, suponía que el estatismo hipertrofiado había restado eficacia a la acción del Estado, sofocado la iniciativa privada y frenado el crecimiento y el desarrollo. Había que dinamizar la economía mediante una competencia más intensa, sobre todo internacional. La reducción de las barreras arancelarias obligaría a las industrias nacionales a ser más eficientes o a cerrar. La competencia internacional actuaría como un herbicida que eliminaría las malezas y racionalizaría la estructura productiva. Al adecuar la estructura productiva al principio de las ventajas comparativas no solo se impulsarían las exportaciones sino también el crecimiento y el desarrollo, porque la exposición a la competencia obligaría a la industria a incorporar las últimas innovaciones tecnológicas.

Se consideraba que los problemas de ineficiencia del sector productivo eran tan agudos que se necesitaba una apertura rápida y unilateral. En materia arancelaria, la ISI había legado numerosas excepciones e incluso aranceles prohibitivos, que era necesario reformar. En 1979 ya se había logrado un arancel uniforme del 11\%.

Gráfica 1

Exportaciones chilenas, 1960-1990

(Millones de dólares de 2005)

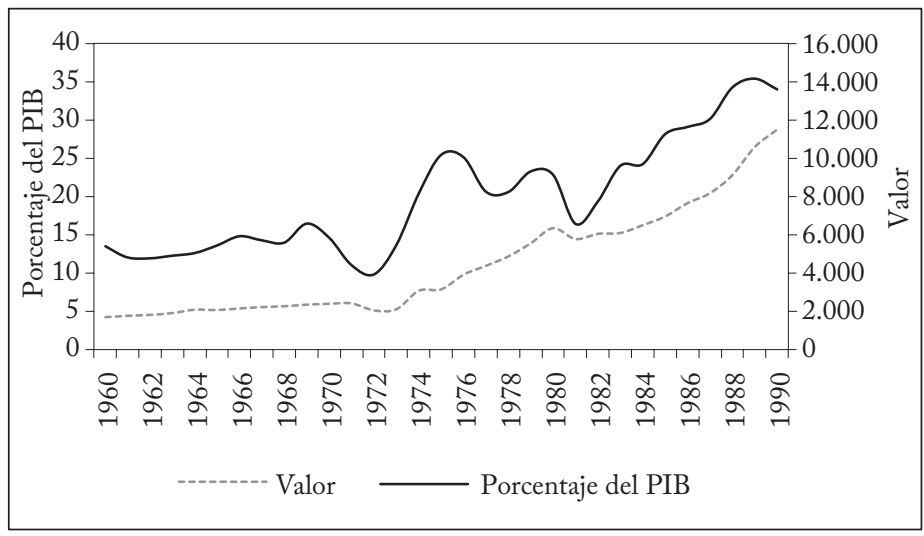

Fuente: World Development Indicators, Banco Mundial. 
Esta política arancelaria estuvo acompañada de cambios institucionales. En 1974 se creó el Instituto de Promoción de Exportaciones de Chile, ProChile y en enero de 1979 la Dirección General de Relaciones Económicas Internacionales (Direcon) para ejecutar y coordinar la política de relaciones económicas internacionales. Con aranceles homogéneos y relativamente bajos, Direcon y ProChile serían la piedra angular de la estrategia de inserción internacional en un marco de reformas más amplio que buscaba crear un clima más favorable para la inversión privada bajo la disciplina que impondría la competencia internacional.

Cuadro 1

Principales exportaciones chilenas, 1975-1990, clasificación SITC v1 (Porcentaje del total en dólares corrientes)

\begin{tabular}{|c|c|c|c|c|}
\hline 1975 & 1980 & 1985 & 1990 & $\%$ \\
\hline Cobre refinado & 50,3 Cobre refinado & 49,8 Cobre refinado & 44,6 Cobre refinado & 46,3 \\
\hline Cobre blíster & $\begin{array}{l}\text { 15,5 Minerales y con- } \\
\text { centrados de cobre }\end{array}$ & $\begin{array}{l}\text { 7,0 Minerales y } \\
\text { concentrados de } \\
\text { cobre }\end{array}$ & $\begin{array}{l}\text { 12,1 Minerales y concen- } \\
\text { trados de cobre }\end{array}$ & 10,1 \\
\hline $\begin{array}{l}\text { Minerales y concentra- } \\
\text { dos de cobre }\end{array}$ & 8,0 Cobre blíster & 6,5 Cobre blíster & 7,5 Cobre blíster & 4,7 \\
\hline Celulosa blanqueada & $\begin{array}{l}\text { 2,6 Minerales y } \\
\text { concentrados de } \\
\text { titanio, vanadio, } \\
\text { molibdeno, etc. }\end{array}$ & $\begin{array}{l}6,2 \text { Celulosa blan- } \\
\text { queada }\end{array}$ & 4,0 Celulosa blanqueada & 3,6 \\
\hline $\begin{array}{l}\text { Otros minerales y con- } \\
\text { centrados no ferrosos }\end{array}$ & 2,2 Madera (planchas) & $\begin{array}{l}\text { 3,2 } \text { Minerales y } \\
\text { concentrados de } \\
\text { titanio, vanadio, } \\
\text { molibdeno, etc. }\end{array}$ & 3,7 Madera (planchas) & 3,3 \\
\hline $\begin{array}{l}\text { Minerales y concentra- } \\
\text { dos de titanio, vanadio, } \\
\text { molibdeno, etc. }\end{array}$ & 2,0 Plata en bruto & 2,9 Plata en bruto & $\begin{array}{l}\text { 2,9 Flejes de madera, } \\
\text { tablillas, etc. }\end{array}$ & 2,9 \\
\hline Madera (planchas) & $\begin{array}{l}\text { 2,0 Celulosa blan- } \\
\text { queada }\end{array}$ & $\begin{array}{l}\text { 2,6 Trozas y láminas } \\
\text { de madera }\end{array}$ & $\begin{array}{l}2,2 \text { Fruta fresca de } \\
\text { hueso }\end{array}$ & 2,2 \\
\hline Celulosa, sin blanquear & $\begin{array}{l}\text { 1,9 Trozas y láminas } \\
\text { de madera }\end{array}$ & $\begin{array}{l}2,4 \text { Fruta fresca de } \\
\text { hueso }\end{array}$ & $\begin{array}{l}\text { 2,1 Celulosa, sin blan- } \\
\text { quear }\end{array}$ & 1,5 \\
\hline Plata en bruto & $\begin{array}{l}\text { 1,5 Cenizas y residuos } \\
\text { de metales no } \\
\text { ferrosos }\end{array}$ & $\begin{array}{l}2,4 \text { Celulosa, sin blan- } \\
\text { quear }\end{array}$ & $\begin{array}{l}\text { 1,6 Trozas y láminas de } \\
\text { madera }\end{array}$ & 1,4 \\
\hline Barras y cables de cobre & $\begin{array}{l}1,4 \text { Celulosa, sin } \\
\text { blanquear }\end{array}$ & 2,1 Madera (planchas) & $\begin{array}{l}\text { 1,6 Peras y membrillos } \\
\text { frescos }\end{array}$ & 1,4 \\
\hline
\end{tabular}

Fuente: UN-COMTRADE.

Cuadro 2

Exportaciones según destino, 1975-1990

(Miles de dólares corrientes)

\begin{tabular}{|c|c|c|c|c|c|c|c|c|}
\hline \multicolumn{2}{|c|}{1975} & \multicolumn{2}{|c|}{1980} & \multicolumn{2}{|c|}{1985} & \multicolumn{3}{|c|}{1990} \\
\hline Destino & Valor & \% Destino & Valor & $\%$ Destino & Valor & $\%$ Destino & Valor & $\%$ \\
\hline $\begin{array}{l}\text { Alemania } \\
\text { Federal }\end{array}$ & 184.023 & $\begin{array}{c}\text { 16,3 Alemania } \\
\text { Federal }\end{array}$ & 451.280 & 13,7 EE.UU. & 398.088 & 16,1 Japón & 1.221 .148 & 19,3 \\
\hline Reino Unido & 126.350 & 11,2 EE.UU. & 392.944 & 12,0 Japón & 341.085 & 13,8 EE.UU. & 753.429 & 11,9 \\
\hline Japón & 120.422 & 10,7 Brasil & 364.262 & $\begin{array}{c}\text { 11,1 Alemania } \\
\text { Federal }\end{array}$ & 292.091 & $\begin{array}{c}\text { 11,8 Alemania } \\
\text { Federal }\end{array}$ & 672.398 & 10,7 \\
\hline Argentina & 112.286 & 9,9 Japón & 337.828 & 10,3 Francia & 207.947 & 8,4 Francia & 533.968 & 8,5 \\
\hline Francia & 89.279 & 7,9 Italia & 263.090 & 8,0 Brasil & 197.901 & 8,0 Brasil & 419.203 & 6,6 \\
\hline Italia & 82.537 & 7,3 Francia & 251.148 & 7,6 Italia & 167.619 & 6,8 Italia & 397.335 & 6,3 \\
\hline EE.UU. & 81.316 & $\begin{array}{l}\text { 7,2 Bélgica- } \\
\text { Luxemburgo }\end{array}$ & 206.108 & $\begin{array}{l}\text { 6,3 Reino } \\
\text { Unido }\end{array}$ & 118.378 & 4,8 Reino Unido & 306.858 & 4,9 \\
\hline Brasil & 72.703 & 6,4 Argentina & 199.779 & $\begin{array}{l}\text { 6,1 Corea del } \\
\text { Sur }\end{array}$ & 112.223 & 4,5 Corea del Sur & 303.781 & 4,8 \\
\hline España & 44.722 & 4,0 Reino Unido & 196.450 & 6,0 Argentina & 70.317 & $\begin{array}{l}\text { 2,9 Otros asiá- } \\
\text { ticos }\end{array}$ & 301.234 & 4,8 \\
\hline Yugoeslavia & 30.471 & 2,7 España & 101.370 & 3,1 España & 64.242 & 2,6 España & 132.617 & 2,1 \\
\hline
\end{tabular}

Fuente: UN-COMTRADE. 
Los efectos de la apertura se sintieron muy pronto, pues las exportaciones aumentaron notablemente. En dólares corrientes, su valor pasó de 1.129 millones en 1975 a 6.312 millones en 1990 . Su importancia en la economía chilena también aumentó, aunque concentrada en bienes primarios de poco valor agregado. El índice Herfindahl-Hirschman (IHH) que mide la concentración mediante la fórmula $I H H=\sum_{i=1}^{N} x_{i}^{2}$, donde $x_{i}$ es la participación del bien $i$ en el valor total, apenas pasó de 0,286 en 1975 a 0,231 en 1991 para los diez principales bienes de exportación.

\section{LOS PRIMEROS GOBIERNOS DE LA CONCERTACIÓN:}

\section{EL REGIONALISMO ABIERTO}

Los gobiernos de la Concertación, que asumieron el poder en 1990, heredaron un sector exportador que había aprendido a someterse a la competencia internacional y mostraba un gran dinamismo. Las reformas crearon un marco institucional apropiado, aunque no sin imperfecciones. El manejo macroeconómico era consistente con el fomento de las exportaciones, salvo quizá la política cambiaria que a veces era errática (Morandé y Tapia,2002), sobre todo antes del régimen de flotación de facto. No obstante, el éxito exportador durante el gobierno militar fue cuantitativo y no cualitativo. A pesar del aumento de las exportaciones no tradicionales, la mayor parte del valor agregado correspondía a bienes primarios. La apertura de la economía había provocado la desindustrialización (Meller, 1996). Y se preguntaba si podía ser revertida por políticas guiadas por el mercado.

Las fuertes críticas de grupos de expertos cercanos a la coalición -en especial del CIEPLAN- de las reformas económicas generaron expectativas o temores -según la posición ideológica- sobre el manejo económico y las reglas del juego que adoptaría el gobierno de Aylwin (Sapelli, 2000). Pero las reformas que se hicieron en los primeros años de gobierno de la coalición no afectaron visiblemente la institucionalidad heredada. Muy pronto quedó claro que los gobiernos mantendrían el esquema de economía abierta (Ffrench-D., 2002). Pero diferían en la mayor preocupación por los aspectos sociales (condensada en el lema "crecimiento con equidad" de la candidatura presidencial de Ricardo Lagos) y en una mayor participación en el escenario político mundial, en el que el país había estado ausente por el boicot a la dictadura (Fermandois, 2005). Esta reinserción internacional también afectaría la política comercial chilena.

Se mantuvo el pragmatismo de la política comercial del régimen de Pinochet, guiada por la conveniencia comercial de entablar 
relaciones económicas con otras naciones y no por conveniencia ideológica. Es decir, como país comerciante o "país fenicio" (Guardia, 2011, 61). La preocupación por mantener suficiente libertad en la agenda comercial cristalizó en la adopción del regionalismo abierto, basado en la reducción de aranceles en negociaciones bilaterales más que multilaterales. Esta decisión era crucial en el contexto mundial de comienzos de los noventa (Meller, 1993), caracterizado por el bloqueo de las negociaciones del GATT y el declive de la hegemonía económica de Estados Unidos, que impulsaron la creación de bloques económicos (la integración europea se profundizó con la firma del Tratado de Maastricht en 1992, y el NAFTA entró en vigencia en 1994). Si bien Chile fue invitado a formar parte del NAFTA (vía fast-track), la integración se concretó en un tratado de libre comercio (TLC), considerando que el NAFTA no posee una política comercial común. Otro ejemplo del afán por mantener la libertad en la política comercial fue la decisión de no ser miembro pleno del Mercosur impulsado por Argentina y Brasil. El gobierno chileno "solo" firmó un TLC, que permitía definir su política sin anuencia de los demás miembros.

A su vez, el lento progreso de la Ronda de Doha -enmarañada por los subsidios agrícolas europeos y estadounidenses- incentivó a los países interesados en avanzar hacia el libre comercio (o al menos reducir aranceles) para buscar alternativas. Además, un TLC es una forma circunscrita de integración económica y no compromete la autonomía de la política comercial de los países firmantes. Para Chile, este calzaba perfectamente en su estrategia de inserción basada en el regionalismo abierto. Además, son compatibles con la definición de los límites entre la acción del Estado y del mercado según el principio de subsidiariedad. E1 Estado construye infraestructura o suministra recursos que el mercado no provee. Pero su uso sigue siendo prerrogativa del sector privado, de modo que se considera una política neutral u horizontal: no fija la dirección del desarrollo según la agenda del Estado, pues subsidia la "demanda”. Esta doctrina que justifica (y legitima) la intervención estatal por fallas de mercado no desafía las ventajas comparativas.

La política comercial de los noventa se puede caracterizar, por ende, como la de un comerciante global (Aggarwal et al., 2004), dispuesto a hacer negocios con cualquier país, sin tocar temas álgidos que los entorpezcan. Se esperaba que el mero crecimiento de las exportaciones provocara una mayor diversificación y un aumento del valor agregado, pero ese objetivo resultó esquivo. 


\section{EN BUSCA DE LA DIVERSIFICACIÓN}

Se entendía que el desarrollo económico implica generar más valor agregado y que se requeriría diversificar las exportaciones, a nivel de países y de productos. La Direcon, encargada de negociar los TLC en colaboración con entidades privadas como la Sociedad de Fomento Fabril (Sofofa), adquirió gran peso en la Cancillería. Los negociadores chilenos muy pronto lograron reconocimiento internacional por su capacidad técnica y su profesionalismo, y en general el trabajo de la Direcon ha sido evaluado en forma muy positiva (Mesquita y Blyde, 2006). Si bien muchos países se sirvieron de los TLC -hasta tal punto que se empezó a hablar de la noodle bowl para referirse a la intricada red de tratados bilaterales que entorpecía su evaluación en términos de creación y desviación de comercio-, Chile es ejemplar, pues ha firmado 22 acuerdos comerciales con 60 países que cubren cerca del 90\% de su comercio exterior, incluidos mercados de difícil acceso como el japonés y el estadounidense. Este resultado confirma la capacidad de los equipos negociadores.

Asia recibió especial atención en la estrategia de diversificación geográfica. El acercamiento a los países asiáticos - en especial de Asia Pacífico-se inició durante el gobierno militar, pero la estructura institucional se consolidó con la incorporación de Chile a foros como APEC (Asia-Pacific Economic Cooperation) en 1994 y FEALAC (Forum of East Asia-Latin America Cooperation) en 1999. Asia hoy ocupa un lugar importante en la red de TLC que Chile ha construido a lo largo de los años (cuadro 3), y la APEC fue un medio de acercamiento y acceso a los gobiernos de esa región. Asia -en particular China- se convertiría en el socio comercial más importante de Chile, desplazando a Europa y Estados Unidos.

La segunda entidad responsable de fomentar la diversificación fue ProChile. Consciente de la estrecha base exportadora, el gobierno decidió reforzar las exportaciones no tradicionales (un término amplio que abarca todas las exportaciones distintas de cobre y sus derivados directos). ProChile canalizaría el apoyo a los exportadores en forma de servicios estandarizados (estudios de mercado, organización de rondas de negocios, participación en ferias internacionales), centrándose en las PYMES ${ }^{1}$ de los sectores no tradicionales.

\footnotetext{
${ }^{1}$ Según la clasificación de la Corfo, aquellas que tienen entre 5 y 199 trabajadores o ventas anuales de 2.400 a 100.000 Unidades de Fomento (UF). Ver INE (2002).
} 
Cuadro 3

Acuerdos comerciales suscritos por Chile, 2014

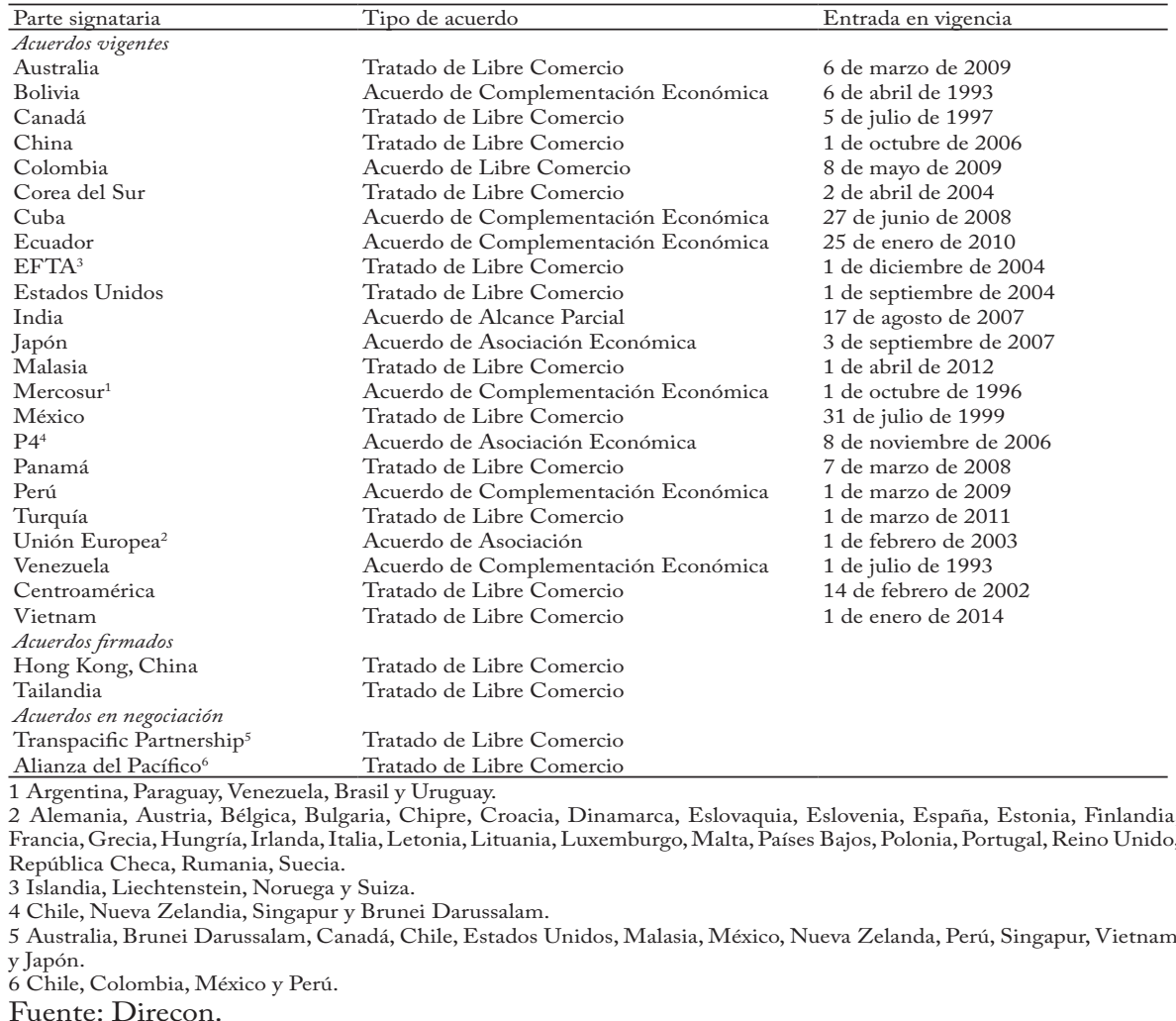

En 2009 ProChile dispuso de 16 millones de dólares para sus actividades de promoción, y entregó al sector privado el 63\% como fondos concursables a través de cofinanciamiento (Martincus, 2010). A mediados de esa década se redujo su presupuesto y, con ello, el apoyo a empresas del sector no agrícola. Centró entonces sus actividades en los sectores agrícola y forestal -entre las que cabe destacar el programa Chile Potencia Alimentaria, al alero del potenciamiento de las marcas sectoriales, durante el gobierno de Piñera- y en mejorar la imagen en el extranjero. Estas actividades se financian con dos fondos especiales: un programa del Ministerio de Agricultura (creado en 1996) que en 2009 llegaba a 7,5 millones de dólares, y un programa de la Presidencia, que pasó de 8 millones de dólares en 2008 a 2 millones en 2009. Hoy esta área ha sido absorbida por la Fundación Imagen de Chile, un organismo estatal autónomo del que ProChile forma parte. 
Los proyectos de diversificación más ambiciosos fueron el desarrollo del sector forestal (que se inició durante el gobierno de Frei Montalva) y del sector salmonero (bajo el alero de la Fundación Chile). Otros casos exitosos fueron los sectores frutícola y vitivinícola, de gran crecimiento en los años ochenta y que ahora han logrado un nivel de madurez. La exportación no tradicional más exitosa fue el vino. El sector vitivinícola se profesionalizó y alcanzó niveles altos y constantes de calidad, pero enfrentaba una debilidad: el vino chileno era casi desconocido en los mercados de Europa y Estados Unidos. La campaña de ProChile para posicionarlo en esos mercados, especialmente en el británico, se considera un ejemplo paradigmático de una campaña de promoción exitosa.

A comienzos de los años ochenta, el vino chileno representaba menos del 1\% del mercado global; en 2001 llegaba al 6,2\% $\%^{2}$. Para ilustrar el gran dinamismo del sector, basta decir que creció un $88 \%$ entre 2000 y 2012 (OIV, 2013), a una tasa anual promedio de un 5,4\%. Entre 2000 y 2012 las exportaciones crecieron un 121\% (OIV, 2013), cerca del 6,8\% anual, y representan más del 50\% de la producción nacional, de modo que es el sector más orientado a las exportaciones de todo el mundo (Felzensztein, 2003). No obstante esos logros cuantitativos y el notable aumento de la calidad y la confiabilidad (Agosín y Bravo, 2009), el nicho que ocupa el vino chileno sigue siendo el de value for money. No es un vino premium que pueda competir con los vinos franceses. Entre 1990 y 2010 no hubo una estrategia para posicionarlo como producto premium. Además, en Inglaterra -donde la campaña de promoción tuvo mucho éxito- la entidad de apoyo, Wines of Chile, cerró sus oficinas. Esa decisión -tal vez inducida por la creencia de que la inserción del producto ya se había logrado y que no se requeriría más apoyo "especial"- es característica de la gobernanza guiada por el mercado.

Aunque el apoyo de ProChile al sector privado busca diversificar la canasta exportable, en la práctica da prioridad a los mercados con mayor potencial de crecimiento (USAID, 2004, 13). Así, la política se centra en la participación de mercado y deja de lado consideraciones como el valor agregado, sin desafiar las ventajas comparativas. Desde los años noventa, la escasa diversificación no ha mejorado la base productiva y solo ha aprovechado las ventajas comparativas del sector agroalimentario logradas en décadas anteriores.

Otras instituciones que apoyan las exportaciones son la Corfo y el Comité de Inversiones Extranjeras, creado en 1974. La Corfo se creó

\footnotetext{
${ }^{2}$ Según datos del Observatorio Español del Mercado de Vino (OEMV).
} 
en 1939 para impulsar la ISI, pero su carácter cambió con la estrategia adoptada en los años setenta. Hoy es un banco de segundo piso que financia al sector privado para suplir ciertas fallas del mercado local de capitales, a través de líneas de crédito específicas o fondos concursables que financian proyectos económica y socialmente rentables que no recibirían financiación de la banca privada. En particular, intenta promover la diversificación y sofisticación del aparato productivo; apoyar sectores con alto potencial de crecimiento, impulsando sus exportaciones; aumentar la innovación en las empresas y en la sociedad de manera sustentable; contribuir al desarrollo de mercados financieros competitivos y sofisticados que financien la inversión; y transformar a Chile en un polo de innovación y emprendimiento global (Corfo, 2013). También en este caso el apoyo se rige por la lógica de las fallas del mercado y el principio de "neutralidad", que dan lugar al uso prolífico de fondos concursables.

El principal instrumento de la Corfo son estos fondos, que asigna conforme al principio de las políticas horizontales: las consideraciones técnicas del mercado definen la asignación de recursos y la dirección de la transformación productiva del país. Es decir, sin la guía o dirección de políticas verticales explícitas. Las políticas sectoriales -que definirían las áreas prioritarias para asignar recursos- son inaceptables en este esquema. En segundo lugar, la inversión extranjera directa es un medio importante de transferencia tecnológica - productiva y administrativa- y puede contribuir a la transformación de la economía receptora. Pero el Comité de Inversión Extranjera también sigue la lógica de las políticas horizontales, y el mercado es el que asigna los capitales provenientes del extranjero.

Confiar en los mecanismos de mercado para lograr el desarrollo económico tiene varios peligros. Es una falacia creer que la asignación de recursos estatales mediante mecanismos como los fondos concursables no distorsiona los incentivos o los precios relativos. En primer lugar porque no existe una política horizontal "pura”. Por definición, la política económica crea ganadores y perdedores, y por tanto siempre beneficia a un sector sobre otro. En segundo lugar, dar fondos al sector privado desencadena la caza de rentas, y hay agentes más eficientes para captarlas que otros. En el caso de la Corfo se requerían conocimientos especializados para llenar los formularios, y había firmas consultoras dedicadas a esa tarea. Por último, pensar que la provisión de recursos por parte del Estado es más importante que el uso de los recursos tiene el peligro de perpetuar la estructura de incentivos en vez de alterarla en favor de actividades con mayor valor agregado. En 
suma, es muy difícil lograr la diversificación productiva confiando la tarea al mercado, como demuestran varias investigaciones recientes (ver Devlin y Moguillansky, 2010).

Para resumir, la política comercial chilena y sus instituciones buscaban avanzar en la dimensión cuantitativa: la diversificación geográfica de las exportaciones chilenas mediante la firma de TLC, y en la cualitativa: diversificar la base exportadora (fomentar las exportaciones "no tradicionales").

\section{LA GOBERNANZA DE LAS EXPORTACIONES}

No obstante, puesto que se seguía pensando que el desarrollo económico sería un producto de las fuerzas de mercado, el encadenamiento crecimiento de las exportaciones, crecimiento económico y desarrollo económico se convirtió en el principio regulador de la estrategia comercial: el libre comercio (impulsado por la vasta red de TLC) incentivaría las actividades compatibles con las ventajas comparativas e impulsaría la innovación en esas actividades. Así, bastaba lograr el objetivo cuantitativo para lograr el objetivo cualitativo. El objetivo de la política y la estructura exportadora desde los años ochenta, incluido el periodo de gobiernos de la Concertación, ha sido mejorar el acceso a los mercados, pues este fomentaría la diversificación.

Este enfoque es forzosamente estático o de corto plazo, puesto que las ventajas comparativas, y el desarrollo del sector exportador en particular y de la economía en general, son determinados por fuerzas endógenas no controladas por el Estado. Así, la única razón para que el Estado intervenga es la optimización a corto plazo, es decir, que se limite a "fijar correctamente los precios" y a eliminar los cuellos de botella que entorpecen el normal funcionamiento de las fuerzas de mercado (el principio de subsidiariedad).

La acción de las instituciones estatales durante los gobiernos de la Concertación refleja claramente esa visión. La Direcon intentaba avanzar hacia el libre comercio firmando TLC (la reducción mutua de aranceles mejoraría la asignación de recursos al reducir las distorsiones de los precios internacionales) y ProChile of recía servicios que mitigaban las fallas de mercado. Es decir, se intentó complementar la acción del sector privado sin pretender dirigirla u orientarla. Si bien los TLC eran coherentes con los objetivos de abrir nuevos mercados, reducir la incertidumbre de los negocios internacionales y "premiar" a las empresas competitivas - pues la apertura implicaba que el motor del crecimiento económico no era el mercado doméstico sino el mercado externo (Wehner, 2011)-, la dirección de la transformación 
económica se dejó en manos del mercado. Así, los instrumentos de la estrategia comercial eran más coherentes con los objetivos cuantitativos (participación de mercado) que con los cualitativos (aumentar el valor agregado).

Es cierto que hubo intentos de diseñar una estrategia que diera más énfasis a la dimensión cualitativa, con políticas más verticales, como el plan de convertir a Chile en un puerto país de América Latina (Gutiérrez, 2005) o en plataforma de negocios ${ }^{3}$, usando su vasta red de TLC. Pero estas iniciativas no prosperaron ${ }^{4}$, debido quizá al uso de fondos concursables como instrumento central de política y a la renuencia a revaluar la orientación hacia el mercado. También cabe mencionar los fallidos intentos de crear o mejorar la imagen país, entre los cuales Chile: All ways surprising, gestionado por ProChile bajo la dirección de Alicia Frohmann, es quizá el más infortunado (Felzensztein, 2008). La falta de definición y de consenso sobre el Chile futuro que se querría construir entorpeció la formulación de una estrategia coherente y sostenida que mejorara la imagen país.

En suma, la doctrina de las ventajas comparativas y la gobernanza impulsada por el mercado fueron dos constantes de la política comercial durante los gobiernos de la Concertación, cuyos resultados se analizan a continuación.

\section{LOS RESULTADOS}

Recordemos que los dos grandes objetivos de la política comercial eran mejorar el acceso a los mercados y mejorar la diversificación de la estructura productiva. En este apartado se presentan los resultados obtenidos entre 1990 y 2010 para evaluarlos a la luz de ambos objeti$\operatorname{vos}^{5}$, considerando también la diversificación geográfica. La apertura de nuevos mercados mejora el acceso de los bienes exportados y crea oportunidades para exportar nuevos productos. Un TLC con un país africano (u otro país con menor grado de desarrollo tecnológico que Chile) puede ser una oportunidad para exportar manufacturas que difícilmente podrían entrar en mercados más sofisticados de Europa o el este asiático.

El primer criterio es el aumento de las exportaciones (gráfica 2). Como proporción del PIB y en valor absoluto estas han crecido en forma casi ininterrumpida (salvo durante la crisis asiática de 1997 y

${ }^{3} \operatorname{Ver}$ [http://www.direcon.gob.c1/1970/01/chile-pais-plataforma-de-negocios/].

${ }^{4}$ Ver [http://www.lasegunda.com/Noticias/Economia/2013/10/885212/paisplataforma-los-obstaculos-para-completar-el-puente-comercial-de-chile-con-asiapacifico].

${ }^{5}$ Los resultados provienen principalmente de Dingemans y Ross (2012). 
la crisis de 2008); aquí cabe destacar el impulso recibido por el súper ciclo de bienes primarios iniciado en 2003 por el empuje global de la demanda china. Entre 1990 y 2010 las exportaciones crecieron un $321 \%$, a un $13 \%$ anual en promedio. En cuanto a su composición (cuadro 4), el cobre sigue siendo el producto de exportación más importante. Incluso un bien de exportación no tradicional como el vino -más allá de que su valor agregado sea pequeño-solo representa en promedio un magro 3\%. La canasta exportadora poco ha cambiado, está compuesta por bienes primarios (recursos naturales) y alimentos; y su concentración se ha mantenido relativamente (como muestra el análisis de algunos índices).

Gráfica 2

Exportaciones chilenas, 1990-2010

(Miles de millones de dólares de 2005)

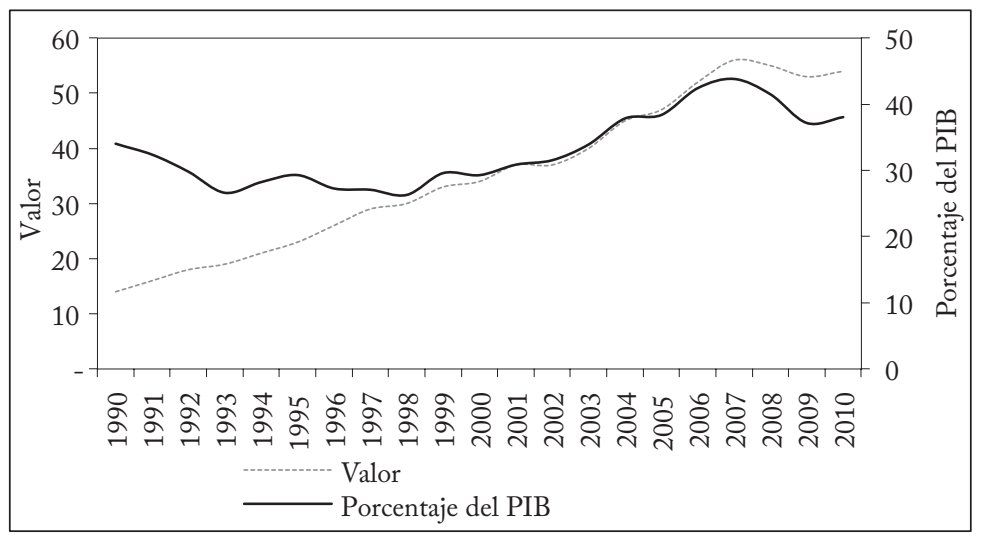

Fuente: World Development Indicators, Banco Mundial.

Cuadro 4

Los diez principales bienes de exportación, 1995-2010

\begin{tabular}{|c|c|c|c|c|c|c|c|}
\hline \multicolumn{2}{|l|}{1995} & \multicolumn{2}{|l|}{2000} & \multicolumn{2}{|l|}{2005} & \multicolumn{2}{|l|}{2010} \\
\hline & $\%$ & & $\%$ & & $\%$ & & $\%$ \\
\hline Cobre refinado & 34,7 & Cobre refinado & 35,7 & Cobre refinado & 34,9 & Cobre refinado & 43,2 \\
\hline $\begin{array}{l}\text { Minerales y concentra- } \\
\text { dos de cobre }\end{array}$ & 15,9 & $\begin{array}{l}\text { Minerales y concentra- } \\
\text { dos de cobre }\end{array}$ & 17,5 & $\begin{array}{l}\text { Minerales y concentra- } \\
\text { dos de cobre }\end{array}$ & 20,1 & $\begin{array}{l}\text { Minerales y concentra- } \\
\text { dos de cobre }\end{array}$ & 24,1 \\
\hline Celulosa blanqueada & 8,6 & Celulosa blanqueada & 6,9 & $\begin{array}{l}\text { Minerales de metales } \\
\text { no ferrosos }\end{array}$ & 9,6 & Cobre blíster & 4,2 \\
\hline Cobre blíster & 3,4 & Vinos y mostos & 5,2 & Celulosa blanqueada & 3,8 & Celulosa blanqueada & 4,2 \\
\hline $\begin{array}{l}\text { Flejes de madera, } \\
\text { madera en tablillas }\end{array}$ & 3,2 & Madera de coníferos & 2,6 & Vinos y mostos & 3,6 & Vinos y mostos & 3,2 \\
\hline $\begin{array}{l}\text { Minerales de metales no } \\
\text { ferrosos }\end{array}$ & 2,8 & Cobre blíster & 2,5 & Cobre blíster & 3,6 & $\begin{array}{l}\text { Minerales de metales } \\
\text { no ferrosos }\end{array}$ & 2,2 \\
\hline Madera de coníferos & 2,5 & $\begin{array}{l}\text { Alcohol metílico, } \\
\text { metanol }\end{array}$ & 2,4 & Madera de coníferos & 2,7 & Frutas de hueso & 1,1 \\
\hline Vinos y mostos & 1,6 & Frutas de hueso & 1,5 & $\begin{array}{l}\text { Alcohol metílico, } \\
\text { metanol }\end{array}$ & 2,3 & Madera de coníferos & 1,0 \\
\hline Frutas de hueso & 1,6 & $\begin{array}{l}\text { Flejes de madera, made- } \\
\text { ra en tablillas }\end{array}$ & 1,5 & Frutas de hueso & 1,2 & $\begin{array}{l}\text { Flejes de madera, made- } \\
\text { ra en tablillas }\end{array}$ & 1,0 \\
\hline $\begin{array}{l}\text { Madera laminada de } \\
\text { coníferos }\end{array}$ & 1,6 & Celulosa, no blanqueada & 1,2 & $\begin{array}{l}\text { Madera elaborada de } \\
\text { coníferos }\end{array}$ & 1,1 & $\begin{array}{l}\text { Barras y alambre de } \\
\text { cobre }\end{array}$ & 1,0 \\
\hline
\end{tabular}

Fuente: UN-COMTRADE. 
En lo que respecta al criterio de diversificación geográfica se observa algo similar (cuadro 5): aunque China se convirtió en el principal socio comercial, la concentración geográfica de las exportaciones no ha sufrido nuevos cambios. Y no es claro que se hayan abierto nuevos mercados. Cabe recordar que en la época de la ISI la economía chilena no era autárquica.

Cuadro 5

Los diez principales socios comerciales (Porcentaje del total de exportaciones)

\begin{tabular}{|c|c|c|c|c|c|c|c|}
\hline 1995 & & 2000 & & 2005 & & 2010 & \\
\hline País & $\%$ & País & $\%$ & País & $\%$ & País & $\%$ \\
\hline Japón & 18,54 & Japón & 13,07 & China & 14,98 & China & 29,93 \\
\hline Estados Unidos & 9,98 & Estados Unidos & 12,85 & Estados Unidos & 13,65 & Japón & 10,87 \\
\hline Brasil & 8,13 & China & 9,15 & Japón & 12,22 & Estados Unidos & 7,92 \\
\hline Corea del Sur & 7,96 & Corea del Sur & 5,86 & Corea del Sur & 6,59 & Corea del Sur & 6,59 \\
\hline Alemania & 7,39 & Italia & 5,78 & Italia & 5,56 & Brasil & 6,15 \\
\hline Otros países de Asia & 7,24 & Brasil & 5,60 & Brasil & 4,95 & Italia & 4,39 \\
\hline Francia & 5,53 & France & 5,50 & Alemania & 4,56 & Otros países de Asia & 3,64 \\
\hline Italia & 4,82 & Reino Unido & 5,15 & France & 4,34 & Alemania & 3,24 \\
\hline Reino Unido & 2,90 & Alemania & 4,98 & Países Bajos & 3,72 & India & 2,73 \\
\hline Argentina & 2,60 & Otros países de Asia & 4,06 & México & 3,67 & México & 2,49 \\
\hline
\end{tabular}

Fuente: UN-COMTRADE.

La imagen que describen los dos cuadros anteriores es reforzada por los cuadros 6 y 7 . E1 cuadro 6 muestra que entre 1990 y 2008 no se exportaron nuevos productos (aunque no se redujo la gama de bienes), tomando un umbral de 50.000 dólares $^{6}$, es decir, la diversificación de las exportaciones fue prácticamente inexistente. Esto lo muestra mejor el cuadro 7, que distingue entre crecimiento en el margen extensivo y en el intensivo. El primero es el aumento de las ventas de productos ya exportados a mercados existentes y el segundo la exportación de nuevos productos a mercados existentes, de productos ya exportados a nuevos mercados o de nuevos productos a nuevos mercados. La exportación de un bien nuevo a un mercado nuevo es el crecimiento en el margen extensivo tipo II; la exportación de un bien nuevo a un mercado existente es el crecimiento en el margen extensivo tipo Ia, y la exportación de un bien ya exportado a un mercado nuevo es el crecimiento en el margen extensivo tipo Ib.

La mayor parte del crecimiento de las exportaciones chilenas corresponde al crecimiento en el margen intensivo, y solo el 4,1\% al crecimiento en el margen extensivo (sobre todo por la exportación de bienes ya exportados a mercados nuevos).

Por su parte, la concentración de la canasta exportadora, considerando productos y destinos (cuadro 8), no ha variado, lo que reafirma

${ }^{6} \mathrm{Si}$ se exporta un bien por menos de 50.000 dólares al año se considera que no existe. Si en 1990 su valor fue de 20.000 dólares y en 2008 de 100.000 es un nuevo producto. 
la imagen anterior. La política exportadora tuvo sin duda gran éxito, pero se basó casi exclusivamente en el aprovechamiento de economías de escala. Se logró con creces el objetivo de mejorar el acceso a los mercados -a lo cual contribuyeron los TLC- pero no el de diversificar las exportaciones (ni en destinos ni en productos).

Cuadro 6

Países seleccionados de América Latina, número de productos exportados ${ }^{1}$

\begin{tabular}{|c|c|c|c|c|c|c|c|}
\hline & \multirow[t]{2}{*}{1990} & \multicolumn{2}{|c|}{2008} & \multicolumn{2}{|c|}{ Nuevos productos } & \multicolumn{2}{|c|}{ Productos que ya no se exportan } \\
\hline & & Total & Variación (\%) & Total & Variación (\%) & Total & Variación (\%) \\
\hline Argentina & 66 & 67 & 2 & 1 & 2 & 0 & 0 \\
\hline Bolivia & 40 & 49 & 23 & 15 & 38 & 6 & 15 \\
\hline Brasil & 66 & 67 & 2 & 1 & 2 & 0 & 0 \\
\hline Chile & 67 & 67 & $O$ & $O$ & $O$ & $O$ & $O$ \\
\hline Colombia & 63 & 67 & 6 & 4 & 6 & 0 & 0 \\
\hline Ecuador & 51 & 61 & 20 & 10 & 20 & 0 & 0 \\
\hline México & 68 & 68 & 0 & 0 & 0 & 0 & 0 \\
\hline Paraguay & 50 & 58 & 16 & 9 & 18 & 1 & 2 \\
\hline Perú & 62 & 66 & 7 & 4 & 6 & 0 & 0 \\
\hline Uruguay & 61 & 64 & 5 & 3 & 5 & 0 & 0 \\
\hline Venezuela & 61 & 59 & -3 & 2 & 3 & 4 & 7 \\
\hline
\end{tabular}

1. A nivel de dos dígitos, CUCI Revisión 2.

Fuente: UN-COMTRADE, Dingemans y Ross (2012).

Cuadro 7

Países seleccionados de América Latina, crecimiento de las exportaciones (Dólares constantes de 2008 y porcentajes)

\begin{tabular}{|c|c|c|c|c|c|c|c|c|c|}
\hline & \multirow{2}{*}{$\begin{array}{c}\text { Crecimiento } \\
\text { total } \\
\text { Dólares } \\
\end{array}$} & \multicolumn{2}{|c|}{ Margen intensivo } & \multicolumn{2}{|c|}{ Margen extensivo Ia } & \multicolumn{2}{|c|}{ Margen extensivo Ib } & \multicolumn{2}{|c|}{ Margen extensivo II } \\
\hline & & Dólares & $\%$ & Dólares & $\%$ & Dólares & $\%$ & Dólares & $\%$ \\
\hline Argentina & 41.908 .657 & 37.921 .985 & 90,5 & 767.685 & 1,8 & 3.218 .058 & 7,7 & 930 & 0,0 \\
\hline Bolivia & 4.221 .157 & 3.665 .666 & 86,8 & 167.837 & 4,0 & 385.234 & 9,1 & 2.420 & 0,1 \\
\hline Brasil & 117.120 .714 & 103.406 .173 & 88,3 & 381.132 & 0,3 & 13.333 .410 & 11,4 & $\cdots$ & 0,0 \\
\hline Chile & 48.333 .456 & 46.374 .130 & 95,9 & $\ldots$ & 0,0 & 1.959 .326 & 4,1 & $\ldots$ & 0,0 \\
\hline Colombia & 22.649 .288 & 20.325 .116 & 89,7 & 1347.289 & 5,9 & 976.883 & 4,3 & $\ldots$ & 0,0 \\
\hline Ecuador & 11.151 .895 & 9.762 .534 & 87,5 & 120.609 & 1,1 & 1.228 .834 & 11,0 & 39.918 & 0,4 \\
\hline México & 222.408 .006 & 219.870 .841 & 98,9 & $\ldots$ & 0,0 & 2.537 .166 & 1,1 & $\ldots$ & 0,0 \\
\hline Paraguay & 1.999 .375 & 1.502 .079 & 75,1 & 10.290 & 0,5 & 486.611 & 24,3 & 395 & 0,0 \\
\hline Perú & 23.629 .593 & 22.920 .015 & 97,0 & 7.876 & 3,0 & 701.599 & 0,0 & 350 & 0,0 \\
\hline Uruguay & 2.606 .881 & 1.461 .283 & 56,1 & 26.565 & 1,0 & 1.119 .002 & 42,9 & 31 & 0,0 \\
\hline Venezuela & 21.318 .792 & 6.133 .959 & 28,8 & 12.198 & 0,1 & 15.172 .632 & 71,2 & 3 & 0,0 \\
\hline
\end{tabular}

Fuente: UN-COMTRADE, Dingemans y Ross (2012).

Aquí conviene mostrar el índice de complejidad de la economía chilena, que intenta captar la sofisticación y la originalidad del conocimiento incorporado en la producción (gráfica 3). A medida que aumenta este índice también aumenta la originalidad del conocimiento. Un valor bajo indica una escasa sofisticación (una alta primarización) de la estructura productiva. Este indicador es relevante porque es uno de los predictores más robustos del crecimiento de largo plazo (Hausmann, 2013). Para Chile, los resultados no son prometedores. El súper ciclo de bienes primarios (2003-2013) afectó en forma negativa la complejidad económica de América Latina y en particular la de Chile. La distancia entre Corea del Sur y América Latina es notable. Y con 
respecto a América Latina, la economía chilena no ha sobrepasado a la de Argentina ni a la de Brasil, y su desempeño no ha sido muy diferente de la de Perú, que se suele considerar menos desarrollada.

Cuadro 8

Países seleccionados de América Latina, índices de concentración ${ }^{1}$

\begin{tabular}{|c|c|c|c|c|c|}
\hline & \multirow[t]{2}{*}{ Índice } & \multicolumn{2}{|c|}{ Productos } & \multicolumn{2}{|c|}{ Socios comerciales } \\
\hline & & 1990 & 2008 & 1990 & 2008 \\
\hline \multirow[t]{4}{*}{ Argentina } & HI1 & 0,060 & 0,058 & 0,055 & 0,064 \\
\hline & $\mathrm{HI} 2$ & 0,244 & 0,242 & 0,235 & 0,254 \\
\hline & OGV & 2,972 & 2,932 & 5,274 & 7,478 \\
\hline & ENT & 4,632 & 4,736 & 5,001 & 5,045 \\
\hline \multirow[t]{4}{*}{ Bolivia } & HI1 & 0,180 & 0,242 & 0,151 & 0,176 \\
\hline & HI2 & 0,425 & 0,492 & 0,388 & 0,419 \\
\hline & OGV & 6,765 & 11,140 & 9,926 & 8,097 \\
\hline & ENT & 3,212 & 2,925 & 3,337 & 3,471 \\
\hline \multirow[t]{4}{*}{ Brasil } & HI1 & 0,046 & 0,044 & 0,073 & 0,047 \\
\hline & $\mathrm{HI} 2$ & 0,215 & 0,211 & 0,270 & 0,217 \\
\hline & OGV & 2,076 & 1,991 & 8,768 & 7,076 \\
\hline & ENT & 4,970 & 5,012 & 5,046 & 5,372 \\
\hline \multirow[t]{4}{*}{ Chile } & HI1 & 0,184 & 0,197 & 0,079 & 0,072 \\
\hline & HI2 & 0,429 & 0,443 & 0,280 & 0,268 \\
\hline & OGV & 11,333 & 12,178 & 6,290 & 6,464 \\
\hline & ENT & 3,477 & 3,403 & 4,458 & 4,559 \\
\hline \multirow[t]{4}{*}{ Colombia } & HI1 & 0,133 & 0,119 & 0,192 & 0,175 \\
\hline & $\mathrm{HI} 2$ & 0,364 & 0,345 & 0,438 & 0,418 \\
\hline & OGV & 7,434 & 6,970 & 12,828 & 14,741 \\
\hline & ENT & 3,758 & 4,200 & 3,873 & 3,913 \\
\hline \multirow[t]{4}{*}{ Ecuador } & HI1 & 0,300 & 0,365 & 0,303 & 0,193 \\
\hline & $\mathrm{HI} 2$ & 0,548 & 0,604 & 0,550 & 0,440 \\
\hline & OGV & 14,628 & 21,384 & 14,201 & 11,981 \\
\hline & ENT & 2,243 & 2,498 & 3,111 & 3,581 \\
\hline \multirow[t]{4}{*}{ México } & HI1 & 0,136 & 0,086 & 0,496 & 0,659 \\
\hline & $\mathrm{HI} 2$ & 0,369 & 0,294 & 0,704 & 0,812 \\
\hline & OGV & 8,244 & 4,870 & 38,355 & 66,268 \\
\hline & ENT & 4,130 & 4,297 & 2,317 & 1,654 \\
\hline \multirow[t]{4}{*}{ Paraguay } & HI1 & 0,233 & 0,172 & 0,141 & 0,093 \\
\hline & HI2 & 0,482 & 0,414 & 0,375 & 0,305 \\
\hline & OGV & 10,856 & 9,015 & 8,112 & 5,780 \\
\hline & ENT & 2,817 & 3,276 & 3,762 & 4,288 \\
\hline \multirow[t]{4}{*}{ Perú } & HI1 & 0,136 & 0,154 & 0,084 & 0,082 \\
\hline & HI2 & 0,369 & 0,392 & 0,290 & 0,287 \\
\hline & OGV & 7,417 & 9,179 & 6,317 & 6,470 \\
\hline & ENT & 3,538 & 3,422 & 4,513 & 4,341 \\
\hline \multirow[t]{4}{*}{ Uruguay } & HI1 & 0,093 & 0,086 & 0,104 & 0,064 \\
\hline & HI2 & 0,304 & 0,294 & 0,323 & 0,254 \\
\hline & OGV & 4,709 & 4,538 & 7,306 & 5,320 \\
\hline & ENT & 4,144 & 4,393 & 4,308 & 4,900 \\
\hline \multirow[t]{4}{*}{ Venezuela } & HI1 & 0,624 & 0,890 & 0,292 & 0,164 \\
\hline & $\mathrm{HI} 2$ & 0,790 & 0,943 & 0,541 & 0,405 \\
\hline & OGV & 37,169 & 51,654 & 18,323 & 8,677 \\
\hline & ENT & 1,631 & 0,523 & 3,204 & 3,102 \\
\hline
\end{tabular}

1. Calculados para socios comerciales y productos a nivel de dos dígitos, CUCI Revisión 2.

HI1 = Índice de Herfindahl; HI2 = Índice de Hirschman; OGV = Índice Ojiva; ENT = Índice de entropía. Fuente: UN-COMTRADE, Dingemans y Ross (2012).

Los pocos trabajos empíricos que exploran los determinantes de la diversificación emplean indicadores de concentración, como el HHI, sin considerar el valor agregado. $\mathrm{El}$ primer tipo de explicaciones incluye variables clave, como la apertura comercial y el desarrollo financiero, 
el tipo de cambio (su volatilidad y su sobrevaluación), la dotación de factores (capital humano), la distancia económica y los choques de términos de intercambio (Agosín et al., 2011). Los resultados de una muestra de países que incluye a Chile indican que ninguno de esos factores incide en la diversificación, salvo la apertura que induce a la especialización (ibíd., 16). De modo que la diversificación no es tanto el resultado de esas variables macroeconómicas como de aspectos más cualitativos, como el desarrollo económico (aunque esto parezca tautológico) y el capital humano. Los trabajos sobre los determinantes de la productividad de las exportaciones también concluyen que el capital humano y el ingreso real (proxy del desarrollo) son los que más inciden (Santos, 2008). Estos hallazgos ayudan a explicar por qué la estrategia chilena, guiada por el mercado, ha tenido resultados decepcionantes en materia de diversificación. El manejo adecuado de variables macro no es suficiente.

Gráfica 3

Complejidad económica, países seleccionados, 1970-2010

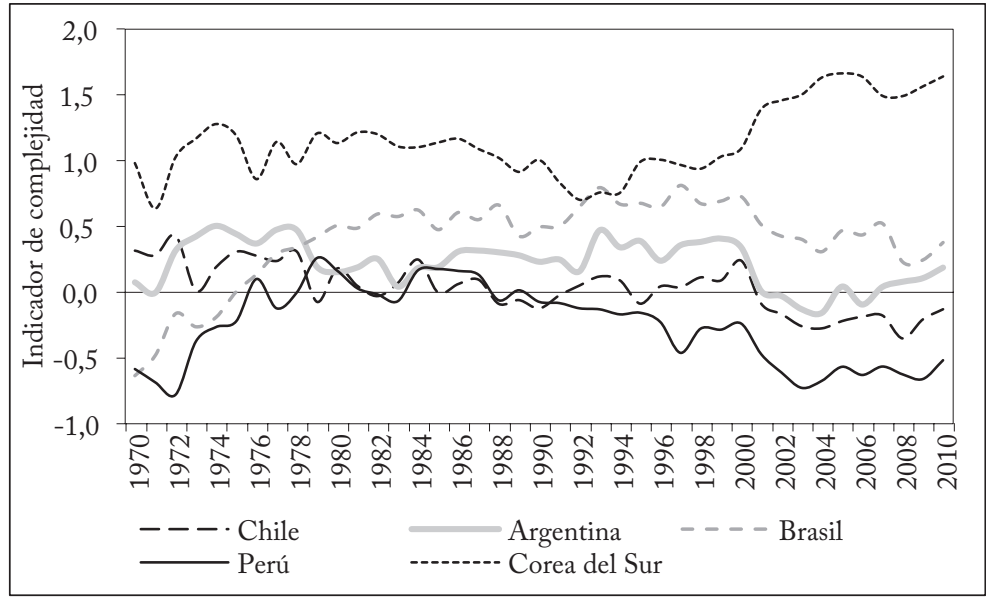

Fuente: Observatory of Economic Complexity, MIT-Harvard.

E1 segundo tipo de explicaciones supone que la diversificación depende de una estrategia explícita, guiada entonces por mecanismos de índole política más que de mercado. Esto es consistente con la experiencia asiática, quizá el caso más sobresaliente de transformación económica impulsada por las políticas industriales (Fishlow, 1994), a pesar de que se haya atribuido ese éxito a la fijación de precios adecuados (World Bank, 1993). No obstante, una estrategia explícita no es garantía de éxito. Los gobiernos pueden fallar por acción u omisión. 
Un trabajo sobre las estrategias de diversificación (medida por un índice de concentración) en África Subsahariana (Cabral y Veiga, 2010) muestra que la corrupción, la transparencia y la rendición de cuentas son determinantes, y que los aspectos político-institucionales son relevantes para el éxito de la estrategia.

El reto de la política exportadora chilena es iniciar una segunda etapa cuyo principal objetivo sea mejorar la calidad de las exportaciones. La primera etapa tuvo éxito, pero ese éxito no debe impedir la evaluación crítica de sus fortalezas y debilidades ni descartar propuestas que incluyan incluso reconsiderar el papel del Estado. Pues, como sugiere la evidencia empírica, la sofisticación de la producción puede ser resultado de las meras fuerzas del mercado. Es necesario articular los esfuerzos con un objetivo común, es decir, pasar de la gobernanza guiada por el mercado a una guiada por el Estado. Este paso requiere nuevas instituciones y cambios en las que ya existen. En particular, se debe replantear el papel de los fondos concursables, que hoy son un subsidio a la demanda.

Cabe preguntar si el país tiene la capacidad institucional para empeñarse en este tipo de estrategia, así su adopción no sea suficiente para lograr éxito, pues no se consideran otros factores como su legitimidad. Si los actores políticos relevantes consideran que no es legítima, se opondrán a ella, sin importar la capacidad institucional. Hecha esta advertencia, consideremos los datos relevantes.

Cuadro 9

Indicadores de gobernanza en países seleccionados

\begin{tabular}{|c|c|c|c|c|c|c|c|}
\hline & & \multicolumn{2}{|c|}{ Chile } & \multicolumn{2}{|c|}{ España } & \multicolumn{2}{|c|}{ Corea del Sur } \\
\hline & Año & Puntaje & Índice & Puntaje & Índice & Puntaje & Índice \\
\hline \multirow[t]{4}{*}{ Participación y rendición de cuentas } & 1996 & 0,65 & 68,3 & 1,33 & 89,9 & 0,62 & 65,9 \\
\hline & 2003 & 0,98 & 79,3 & 1,25 & 90,4 & 0,66 & 67,3 \\
\hline & 2008 & 1,00 & 77,4 & 1,18 & 87,5 & 0,62 & 68,3 \\
\hline & 2013 & 1,09 & 84,4 & 0,97 & 77,3 & 0,69 & 68,3 \\
\hline Estabilidad política y & 1996 & 0,62 & 64,4 & 0,16 & 50,5 & 0,52 & 63,0 \\
\hline \multirow[t]{3}{*}{ ausencia de violencia/terrorismo } & 2003 & 0,75 & 70,2 & $-0,04$ & 39,9 & 0,21 & 50,5 \\
\hline & 2008 & 0,41 & 58,9 & $-0,40$ & 30,1 & 0,40 & 57,9 \\
\hline & 2013 & 0,37 & 60,2 & 0,01 & 46,9 & 0,24 & 56,9 \\
\hline \multirow[t]{4}{*}{ Eficacia gubernamental } & 1996 & 1,28 & 87,8 & 1,62 & 90,2 & 0,63 & 73,2 \\
\hline & 2003 & 1,24 & 86,8 & 1,90 & 94,6 & 0,93 & 78,5 \\
\hline & 2008 & 1,17 & 84,5 & 0,92 & 79,1 & 1,05 & 81,6 \\
\hline & 2013 & 1,25 & 86,1 & 1,15 & 82,9 & 1,12 & 82,3 \\
\hline \multirow[t]{4}{*}{ Calidad regulatoria } & 1996 & 1,64 & 96,6 & 1,14 & 84,8 & 0,48 & 66,2 \\
\hline & 2003 & 1,47 & 91,2 & 1,31 & 88,7 & 0,75 & 73,5 \\
\hline & 2008 & 1,54 & 92,7 & 1,24 & 86,9 & 0,72 & 73,3 \\
\hline & 2013 & 1,48 & 91,9 & 0,93 & 79,0 & 0,98 & 79,9 \\
\hline \multirow[t]{4}{*}{ Estado de derecho } & 1996 & 1,05 & 84,2 & 1,39 & 90,9 & 0,75 & 68,9 \\
\hline & 2003 & 1,24 & 87,6 & 1,26 & 88,5 & 0,78 & 73,2 \\
\hline & 2008 & 1,27 & 88,5 & 1,17 & 86,1 & 0,85 & 76,4 \\
\hline & 2013 & 1,34 & 87,7 & 1,00 & 81,0 & 0,94 & 78,8 \\
\hline \multirow[t]{4}{*}{ Control de la corrupción } & 1996 & 1,45 & 89,8 & 1,05 & 83,9 & 0,27 & 64,9 \\
\hline & 2003 & 1,29 & 86,3 & 1,35 & 90,2 & 0,48 & 71,7 \\
\hline & 2008 & 1,32 & 90,3 & 1,11 & 82,5 & 0,37 & 77,0 \\
\hline & 2013 & 1,52 & 90,4 & 0,81 & 75,1 & 0,55 & 70,3 \\
\hline
\end{tabular}

equivale a una mejor posición. 
Desde 1996 el Banco Mundial publica indicadores institucionales que recopilan otros indicadores. $\mathrm{El}$ proyecto incluye seis áreas: participación y rendición de cuentas, estabilidad política y ausencia de violencia, eficacia gubernamental, calidad regulatoria, Estado de derecho y control de corrupción, todas relevantes para evaluar la factibilidad de una estrategia comercial orientada por el Estado. El cuadro 9, que muestra los resultados, indica que Chile ha mejorado en esas seis áreas y que de acuerdo con el índice se sitúa en el 15\% más alto, salvo en Participación y Estabilidad, que pertenecen al ámbito más estrictamente "político", lo que indica que la institucionalidad chilena es de tipo jerárquico o autoritario (Montecinos, 2003), más que participativo. Como ya se señaló la legitimidad es relevante cuando el Estado pasa a ser responsable del éxito de la estrategia comercial, de modo que la participación y la rendición de cuentas son esenciales. Además, la inestabilidad política puede debilitar los esfuerzos del gobierno para articular la estrategia comercial.

Los indicadores de gobernabilidad son bastante similares a los de países que en las últimas décadas llegaron a ser más industrializados partiendo de una posición similar a la de Chile (España y Corea del Sur). Esto sugiere que Chile está en condiciones de adoptar una gobernanza menos guiada por el mercado.

\section{CONCLUSIONES}

Desde los años ochenta Chile cuenta con una institucionalidad y un conjunto de políticas económicas que atribuye al sector externo el papel de motor del crecimiento económico. La construcción de una economía abierta se realizó al amparo de una gobernanza guiada por el mercado que supervisaba la estrategia exportadora para mejorar el acceso a los mercados y diversificar la oferta. La labor de instituciones como Direcon y ProChile y la firma de numerosos TLC fueron esenciales para el notable crecimiento de las exportaciones. Pero ese crecimiento cuantitativo opaca los magros resultados en materia de diversificación. El valor agregado sigue siendo escaso y la sofisticación baja. Chile continúa exportando cobre poco procesado.

Este artículo sugiere que una de las causas de este resultado decepcionante es el supuesto teórico subyacente a la gobernanza guiada por el mercado. Creer que el cambio en la estructura productiva -en particular un cambio que aumente el valor que agrega a los bienes y servicios producidos en el país- es resultado exclusivo de las fuerzas de mercado no tiene respaldo empírico ni es teóricamente convincente. Para diversificar la exportaciones, una alternativa a la actual gobernan- 
za es la que se basa en mecanismos "burocráticos"(políticas verticales), que guía en forma activa la transformación productiva. Esta estrategia incluiría aspectos de otros ámbitos de política. Entre otras cosas una mayor coherencia entre la política exportadora y la política exterior, y otras políticas económicas, como la cambiaria, que no debería ser tan errática. La mayor articulación en pos de un objetivo común obligaría a tomar distancia del principal instrumento que han utilizado Corfo y ProChile y, por tanto, a reconsiderar el papel del Estado.

En síntesis, la discusión sobre la política exportadora se debería concentrar en el uso de los recursos y no en la cantidad de recursos que el Estado pone a disposición del sector privado. Para diseñar una estrategia que determine el uso de los recursos públicos quizá requiera volver a pensar en estrategias nacionales de desarrollo (o "proyectos país”), lo que significaría tomar distancia de la gestión micro a la que son tan propensos los diseñadores de política chilenos.

El legado de la política exportadora de los gobiernos de la Concertación no debe dar lugar a la autocomplacencia, pues se corre el peligro de no hacer los ajustes necesarios; ajustes que países vecinos como Perú ya están haciendo. Es claro que esa política exportadora logró uno de sus objetivos, pero es hora de lograr el segundo, diversificación, tan esquivo en nuestra historia económica.

Un paso en esa dirección es volver a discutir el papel del Estado y el del mercado, pues los procesos económicos son tan complejos que la relación entre ambos es más orgánica de lo que admite el principio de subsidiariedad. E1 Estado no es un bombero que apaga incendios y se retira; hay que desmontar el tabú sobre el papel del Estado. Una mayor participación del Estado en la economía no ahoga forzosamente la iniciativa privada, como demuestra la experiencia asiática. Es cierto que se deben superar los errores y excesos del pasado, y considerar que esa mayor participación exigirá mayor robustez de las instituciones políticas, pero este es un desafío que debe enfrentar toda sociedad en el proceso de desarrollo.

\section{REFERENCIAS BIBLIOGRÁFICAS}

1. Aggarwal, V.; R. Espach y J. Tulchin, The strategic dynamics of Latin American trade, Stanford, Stanford University Press, 2004.

2. Agosín, M. "Reformas comerciales, exportaciones y crecimiento", R. Ffrench-D. y B. Stallings, eds., Reformas, crecimiento y politicas sociales en Chile desde 1973, Santiago de Chile, LOM, 2000.

3. Agosín, M. y C. Bravo-O. "The emergence of new successful export activities in Latin America: The case of Chile", research network working paper R-552, Washington DC, IADB, 2009. 
4. Agosín, M.; R. Álvarez y C. Bravo-O. "Determinants of export diversification around the world: 1962-2000", documentos de trabajo 605, Santiago, Banco Central de Chile, 2011.

5. Cabral, M. y P. Veiga. "Determinants of export diversification and sophistication in Sub-Saharan Africa”, FEUNL working paper series 550, Lisboa, 2010.

6. Devlin, R. y G. Moguillansky, Alianzas público-privadas para una nueva visión estratégica del desarrollo, Santiago de Chile, NU, Secretaría General Iberoamericana, 2010.

7. Dingemans, A. y C. Ross. "Free trade agreements in Latin America since 1990: An evaluation of export diversification", Cepal Review 108, 2012, pp. 27-48.

8. Felzensztein, C. "Chilean wines: Rethinking successful strategies for the UK market", ECCH Collection, Glasgow, 2003.

9. Felzensztein, C. "Chile - All ways surprising", K. Dinnie, ed., Nation branding: Concepts, issues, practice, Ámsterdam, Elsevier, 2008.

10. Fermandois, H, J. Mundo y fin de mundo: Chile en la politica mundial, 1900-2004, Santiago, Universidad Católica de Chile, 2005.

11. Ffrench-D., R. Economic reforms in Chile: From dictatorship to democracy, Ann Arbor, University of Michigan Press, 2002.

12. Fishlow, A. Miracle or design?: Lessons from the East Asian experience, Washington DC, Overseas Development Council, 1994.

13. Guardia, A. "La inconclusa inserción económica-comercial de Chile", J. Ensignia et al., eds., Politica exterior en el Chile post Concertación: ¿quo vadis?, Santiago de Chile, Friedrich Ebert Stiftung-Fundación Chile 21, 2011.

14. Gutiérrez, H. "Chile and Asia-Pacific: The economic connection", J. Faust et al., eds., Latin America and East Asia. Attempts at diversification, Münster, LIT-KIEP, 2005.

15. Hausmann, R. The atlas of economic complexity: Mapping paths to prosperity, Cambridge, Mass., MIT Press, 2013.

16. INE. "Primera encuesta de las micro, pequeñas y medianas empresas", Boletin Informativo del Instituto Nacional de Estadisticas, enero de 2002.

17. Martincus, C. V. "Odyssey in international markets. An assessment of the effectiveness of export promotion in Latin America and the Caribbean", Washington DC, IADB, 2010.

18. Meller, P. "América Latina en un eventual mundo de bloques económicos”, P. Meller y A. Butelmann, eds., Estrategia comercial chilena para la década del 90, Santiago de Chile, CIEPLAN, 1993.

19. Meller, P. Un siglo de economía politica chilena (1890-1990), Santiago de Chile, Editorial Andrés Bello, 1996.

20. Mesquita M., M. y J. Blyde. "Chile's strategy: Is there room for improvement?", IDB-INTAL working paper 21, Buenos Aires, 2006.

21. Montecinos, V. Economic policy making and parliamentary accountability in Chile, Ginebra, United Nations Research Institute for Social Development, 2003.

22. Morandé, F. y M. Tapia. "Política cambiaria en Chile: el abandono de la banda y la experiencia de flotación”, Economía Chilena 5, 3, 2002, pp. 67-94. 
23. OIV. Statistical report on world vitiviniculture, París, OIV, 2013.

24. Rumelt, R. P. Good strategy, bad strategy: The difference and why it matters, Nueva York, Crown Business, 2011.

25. Salazar, G. y J. Pinto. Historia contemporánea de Chile III. La economía: mercados, empresarios y trabajadores, Santiago de Chile, LOM, 2002.

26. Santos-P., A. "Export productivity and specialization in China, Brazil, India and South Africa”, UNU-WIDER research paper 2008/28, Helsinki, 2008.

27. Sapelli, C. "The political economy of the Chilean transition to democracy", Cuadernos de Economía 37, 112, 2000, pp. 537-556.

28. USAID. "Best practices in export promotion", Washington DC, USAID, 2004.

29. Wehner, L. “Chile's rush to free trade agreements”, Revista de Ciencia Politica 31, 2, 2011, pp. 207-226.

30. World Bank. The East Asian miracle: Economic growth and public policy, Nueva York, Oxford University Press, 1993. 